\title{
The heterogeneous effects of cigarette prices on brand choice in China: implications for tobacco control policy
}

\author{
Jing Li, ${ }^{1}$ Justin S White, ${ }^{2}$ Teh-wei Hu, ${ }^{1}$ Geoffrey T Fong, ${ }^{3,4,5}$ Jiang Yuan ${ }^{6}$
}

${ }^{1}$ School of Public Health, University of California at Berkeley, Berkeley, California, USA

${ }^{2}$ Stanford Prevention Research Center, Stanford University, Stanford, California, USA ${ }^{3}$ Department of Psychology, University of Waterloo, Waterloo, Ontario, Canada ${ }^{4}$ Ontario Institute of Cancer Research, Toronto, Ontario, Canada

${ }^{5}$ School of Public Health and Health Systems, University of Waterloo, Ontario, Canada ${ }^{6}$ Office of Tobacco Control Center for Disease Control and Prevention, Beijing, China

\section{Correspondence to}

Jing Li, School of Public Health, University of California at Berkeley, 274 University Hall, Berkeley, CA 94720, USA; jingli86@berkeley.edu

Received 9 July 2014 Accepted 16 March 2015 Published Online First 8 April 2015
CrossMark

To cite: Li J, White JS Hu T-wei, et al. Tob Control 2015;24:iii25-iii32.
ABSTRACT
Background China has long kept its tobacco taxes below international standards. The Chinese government has cited two rationales against raising tobacco tax, namely, the unfair burden it places on low-income smokers and the ability of consumers to switch to cheaper brands.

Objective This study examines how different socioeconomic subgroups of Chinese smokers switch brands in response to cigarette price changes.

Methods We model smokers' choice of cigarette tier as a function of tier-specific prices. We examine heterogeneous responses to prices by estimating mixed logit models for different income and education subgroups that allow for random variation in smokers' preferences. We use data from three waves of the longitudinal International Tobacco Control China Survey, collected in six large Chinese cities between 2006 and 2009.

Findings Low-income and less educated smokers are considerably more likely to switch tiers (including both up-trading and down-trading) than are their highsocioeconomic status (SES) counterparts. For those in the second-to-lowest tier, a $¥ 1$ ( $\$ 0.16$, or roughly $25 \%$ ) rise in prices increases the likelihood of switching tiers by $5.6 \%$ points for low-income smokers and $7.2 \%$ points for less educated smokers, compared to $1.6 \%$ and $3.0 \%$ points for the corresponding high-SES groups. Lowincome and less educated groups are also more likely to trade down compared to their high-SES counterparts.

Conclusions Only a small percentage of low-income and less educated Chinese smokers switched to cheaper brands in response to price increases. Hence, the concern of the Chinese government that a cigarette tax increase will lead to large-scale brand switching is not supported by this study.

\section{INTRODUCTION}

China ratified the Framework Convention on Tobacco Control (FCTC) in 2005. A key provision of the FCTC is to raise the price of cigarettes through taxation, in recognition of smokers' sensitivity to cigarette prices. Nevertheless, the Chinese government has been reluctant to raise cigarette prices through taxation, evidenced by the fact that the government enacted a complicated reclassification of cigarette price levels and tax rates in 2009, but explicitly banned producers from passing the tax increase onto consumers. ${ }^{1}$ One barrier with respect to raising the cigarette tax is the belief among some Chinese political leaders that cigarette taxes place an unfair burden on low-income smokers. ${ }^{2}$
Another barrier to further tax increase is that some Chinese political leaders have questioned the effectiveness of using cigarette taxes to control tobacco use. They believe that given the very wide price range of cigarettes in China-from $¥ 2$ to more than $¥ 100$ ( $¥ 1=\$ 0.16$ ) per pack—smokers can easily switch to cheaper brands in response to a tax-induced price increase, thus maintaining the same cigarette consumption. Government officials frequently invoke this argument in private conversations. While this reasoning may seem compelling, no existing studies have quantified the magnitude of such switching behaviour, to our knowledge.

In an earlier paper using several waves of the ITC (International Tobacco Control) China Survey data, we addressed the effect of cigarette prices on brand switching among the entire smoking population and found the magnitude of switching to be moderate but non-trivial: a $¥ 1$ change in the price of cigarettes alters the tier choice of $4-7 \%$ of smokers, depending on the starting tier. ${ }^{3}$ However, we did not examine the possible differential effects of price changes among different socioeconomic groups of the population, which is particularly important for policymakers concerned about the relative financial burden of increased taxes on lowincome smokers. The purpose of this paper is to provide empirical evidence about the effect of cigarette prices on the magnitude of brand switching among various socioeconomic groups of smokers in China and to address the implications for tobacco tax policy for tobacco control.

The rest of this paper is organised as follows. Section 2 details the methods, including data, measures and analytical strategy. Section 3 presents the descriptive and multivariate results. Section 4 discusses the implications of our findings for tobacco control policy in China and other countries.

\section{METHODS}

Data

Data for this study come from the ITC China Survey, an individual-level, longitudinal survey of smoking behaviour among adults in China. Our analytical sample is derived from the first three waves of the ITC China Survey, fielded in 2006, 2007-2008 and 2009, in six cities of China: Beijing, Shanghai, Guangzhou, Shenyang, Changsha and Yinchuan. These cities are diverse and broadly representative of China's urban areas. A multistage clustered sampling method was employed at the city level, yielding approximately 800 respondents per city and wave. 
As the objective of this paper is to track smokers' brand-switching behaviour over time, we restricted our sample to 4632 continuing smokers who participated in at least two waves of the ITC China Survey. After applying further restrictions described in detail below, our final analytic sample included 3477 individual smokers who constituted 8552 person-years. Overall retention in our final sample is $82 \%$.

\section{Measures}

Our dependent variable is the market segment (ie, grade or tier) in which a smoker's chosen brand falls in a given wave. We construct this variable using information on the most recent purchase of cigarettes reported by each smoker. Specifically, respondents were asked to provide the brand family and variety, total amount paid and quantity bought for cigarettes that they most recently purchased for themselves. Cigarettes in a brand family are produced by the same manufacturer. Meanwhile, one brand family often contains several brand varieties that are of different prices. For instance, under one brand family such as 'Double Happiness', there are different brand varieties such as 'Hard' and 'Soft'. Often, different brand varieties with the same brand family can belong to different price tiers.

We followed several steps in assigning a tier to each smoker's last purchased cigarettes. First, we computed the per-pack cigarette price by dividing the total amount paid by number of packs bought (the vast majority of cigarette packs in China contain 20 cigarettes each). For quantity reported in cartons, we multiplied the number of cartons by 10 to obtain the number of equivalent packs. Second, we validated the self-reported information using retail price data collected in the same six cities at the same time as Wave 3. Overall, the retail prices were extremely similar to average brand-specific prices from the Wave-3 survey data. For the eight most frequently purchased brand varieties, the citylevel average retail price and the city-level median self-reported survey price were identical in all markets for five varieties and differed by less than $¥ 0.5$ ( $4 \%$ or less) for the remaining three varieties.

Third, we assigned a unique code to each brand variety using the Universal Product Code on the barcode of each pack. For cases in which the preassigned code was missing and a descriptive name was entered in the 'Other' variety and family fields, we manually assigned a brand variety code based on the names provided by respondents. Based on this procedure, we successfully assigned a brand variety code to $78 \%$ of all observations, which consist of 3477 individual smokers as our final sample. Next, we calculated the median price for each brand variety in each city at each wave as the basis for assigning price tiers.

Finally, we sorted brand varieties into price tiers using the sixgrade classification system of allocation prices (analogous to producer prices) that the Chinese government uses to assess excise taxes. For purposes of consistency, we use the same classification for all three waves despite the fact that there was a minor adjustment of cigarette classification and profit margins by the Chinese government in $2009^{4}$ (we provide more explanation of this below). Since the purpose of sorting brand varieties into price tiers is to divide the cigarette market into meaningful segments from the perspective of consumers instead of producers, only the retail prices matter. We converted allocation prices into retail prices using a standard formula reported in Gao et al. ${ }^{5}$ Table 1 shows the retail price ranges for each tier. Since data were sparse at high prices, we combined the three most expensive grades (grades 1, 2 and 3 ) into a single tier (Tier 1). Hence, our final classification included four price tiers. In the rest of the paper, we refer to the tiers with the most expensive cigarettes as Tier 1 and those with the cheapest cigarettes as Tier 4. We assigned each observation to a price tier based on the range into which its by-city median brand variety price fell. For instance, if a smoker in Beijing purchased a soft pack of White Sand in Wave 1 , which has a median price of $¥ 5$, then we assigned this person-year observation to Tier 3 .

Our key independent variable is the market price per pack for each tier in a given wave. We used nominal prices, as China's cigarette price index indicates that inflation was negligible during the study period. In order to account for any recall and reporting biases in the self-reported price measures, we used the median price of all cigarette brands that fall into a given price tier as that tier's market price. Variation in relative median prices of tiers comes from two sources. First, the six cities surveyed are located in different provinces of China, and each province has cigarette factories that produce their own set of brands. ${ }^{6}$ Each city thus has a slightly different composition of brands offered to local consumers. Accordingly, brands not manufactured locally are transported from other cities and provinces and their prices are influenced by random fluctuations in the costs of transportation and handling, which is plausibly unrelated to local demand.

Second, in 2009, the Chinese government implemented an adjustment in its tobacco tax structure in order to raise revenue, which effectively decreased the profit margin on the lowerpriced cigarettes relative to higher-priced cigarettes. ${ }^{4}$ The government prohibited the resulting tax increase from being passed on directly to smokers; therefore, the retail price of a given cigarette brand was left unchanged. ${ }^{2}$ However, the tobacco industry responded by decreasing the production of low-priced cigarettes that became less profitable and increasing the production of high-priced cigarettes that became more profitable. This leads to a change in distribution of production, which in turn decreased the availability of cheap cigarettes (ie, those with a per-pack price below $¥ 3$ ) nationwide and raised the median price in the lower tiers, as within each tier the more expensive brands have become more available compared to the less expensive ones. ${ }^{4}$ This is meaningful to our study as our price measure is not the retail price of any particular brand of cigarettes, but is the median price of all cigarette brands in a given tier, which is more influenced by the distribution of prices on the cigarette market. In addition, the tax adjustment likely affected different cities differently because of the heterogeneity in the composition of brands produced across local markets.

Our regressions control for a variety of demographic characteristics of smokers: gender, age, income, education and average number of cigarettes consumed per day at baseline. Gender, income and education are coded as categorical variables, whereas age and baseline consumption are coded as continuous variables. We constructed socioeconomic subgroups for income and education, as detailed below. We also added city and wave fixed effects to control for time-invariant and cityspecific unobserved factors as well as for aggregate trends that are constant across cities. As brand-specific advertising and marketing are banned in China, these are unlikely to bias our results.

\section{Analytical strategy}

Our estimation approach uses a mixed logit model that describes smokers' choices among different tiers of cigarettes. The value in this particular approach in comparison with other discrete choice models such as conditional logit is its ability to allow for random variation in smokers' tastes for different brands and estimation of individual-specific parameters. ${ }^{7}$ Instead of 
Table 1 Cigarette retail prices in China by tier, 2009

\begin{tabular}{lllllrr}
\hline Grade & Tier & $\begin{array}{l}\text { Retail price } \\
(¥ / \text { pack) }\end{array}$ & Producer profit (\%) & Retail profit (\%) & Smoker-years (N) & Smoker-years (\%) \\
\hline 1 & & {$[29.76, \infty)$} & 51.5 & 15 & 59 & 0.7 \\
2 & 1 & {$[18.95,29.76)$} & 40.8 & 15 & 150 & 1.8 \\
3 & & {$[8.97,18.95)$} & 33.3 & 15 & 955 & 11.3 \\
4 & 2 & {$[5.15,8.97)$} & 33.3 & 10 & 2345 & 27.7 \\
5 & 3 & {$[2.65,5.15)$} & 25 & 10 & 3830 & 1114 \\
6 & 4 & {$[0,2.65)$} & 17.6 & 10 & 8453 & 13.2 \\
\end{tabular}

Note: Retail price ranges are calculated according to the formula $\left(\right.$ Gao et $\left.a l^{5}\right)$ : Retail Price=Allocation Price $\times(1+$ Producer $\pi) \times(1+$ Retail $\pi) \times(1+V A T)$, where $\pi$ denotes profit and VAT is the value-added tax. The ranges for profits come from Gao, Zheng and Hu (2011). For retail price ranges, a bracket denotes a closed interval and a parenthesis denotes an open interval. Tiers 4-6 are combined for analysis due to small cell sizes. Cell counts and proportions are survey weighted. The unweighted sample size is 8552 person-years from 3477 smokers.

assuming a fixed model parameter (eg, coefficient on price) for each individual in the data and producing an estimate for that parameter, the mixed logit model allows the assumption that the parameter of interest is a random variable following a certain distribution, most commonly assumed to be normal, in the population. Accordingly, the mixed logit model produces estimates of the mean as well as the SD of the parameter of interest that is assumed to be random, which capture the average magnitude of the random variable as well as the extent of its variation in the sample.

In setting up the model, we assume that a utility-maximising smoker faces a choice among $\mathrm{J}$ alternative cigarette quality tiers in each of $\mathrm{T}$ choice situations. The utility that smoker $\mathrm{i}$ obtains from tier choice $\mathrm{j}$ in choice situation $\mathrm{t}$ is a function of observed and unobserved factors:

$$
\mathrm{U}_{\mathrm{ijt}}=\alpha_{\mathrm{i}} \mathrm{p}_{\mathrm{ijt}}+\beta_{\mathrm{j}}^{\prime} \mathbf{X}_{\mathrm{it}}+\omega_{\mathrm{ij}}+\varepsilon_{\mathrm{ijt}}
$$

where $\mathrm{p}_{\mathrm{ijt}}$ is the market price of tier $\mathrm{j}$ faced by smoker $\mathrm{i}$ at time $\mathrm{t} ; \alpha_{\mathrm{i}}$ is the smoker-specific coefficient on price; $X_{\mathrm{it}}$ is a vector of observed smoker characteristics including wave and city fixed effects; $\beta_{j}$ is a vector of coefficients specific to tier $j$ on observed smoker characteristics; $\omega_{\mathrm{ij}}$ represents the time-invariant unobserved component of smoker-specific utility from cigarette tier $j$; and $\varepsilon_{\mathrm{ijt}}$ captures time-varying unobserved factors that affect smoker i's choice and is assumed to be distributed i.i.d. extreme value. Smoker i maximises utility by choosing the cigarette quality tier that yields the highest utility: $\operatorname{Pr}\left(\operatorname{Tier}_{\mathrm{it}}=\mathrm{k}\right)=\operatorname{Pr}$ $\left(\mathrm{U}_{\mathrm{ikt}}>\mathrm{U}_{\mathrm{ijt}}\right.$, for all tiers $\left.\mathrm{j} \neq \mathrm{k}\right)$.

In implementing the mixed logit model, we assume that the price coefficient $\alpha_{\mathrm{i}}$ and tier-fixed effects $\omega_{\mathrm{ij}}$ are random variables that take on different values across smokers ('random coefficients'), reflected by the i subscript, whereas the vector of coefficients on observed characteristics are assumed to be fixed ('fixed coefficients'). We think these are reasonable assumptions given that different smokers may respond to cigarette price changes differently (even within a group with similar socioeconomic status (SES)), and smokers are also likely to have varying tastes over cigarettes in a given quality tier even after controlling for observable characteristics.

We estimate the model by simulating the log-likelihood function. Since the model allows for an individual-specific price parameter $\alpha_{i}$ and tier dummies $\omega_{i j}$, the estimated parameters consist of the means as well as the SDs of the distributions of $\alpha_{i}$ and $\omega_{\mathrm{ij}}$ across our sample of smokers.

In performing the estimation, we divided the sample in two ways for the purpose of investigating the heterogeneous effects of prices on cigarette tier choice across SES subgroups. Note that although the mixed logit model allows for heterogeneous price coefficients across individuals, it does not permit direct analysis on how price effects vary by SES if estimated on the full sample only. The survey asked respondents to report their monthly household income in one of four categories: below $¥ 1000, ¥ 1000-2999$ ， $¥ 3000-4999$ and at or above $¥ 5000$. In addition, there were four categories of educational attainment: primary school or less, at least some middle school, at least some high school and beyond high school. In our analysis, we defined the high-income group as having monthly income at or above $¥ 3000$ (approximately \$483), compared to a low-income group of less than $¥ 3000$. Independently, smokers were classified as more educated if they had at least some high school education and less educated if they had no high school education. Although our choice of SES cut-offs is constrained by the information available in the survey data, these cut-offs appear to accord with the distribution of income and education at the national level. Mean monthly household income among urban residents in China was about $¥ 3600$ in 2007 . $^{8}$ In addition, about $60 \%$ of Chinese citizens had received education beyond middle school in 2010. ${ }^{9}$ We estimated the model first for the full sample and then for these four subgroups separately.

Given that the coefficients from a mixed logit model are difficult to interpret directly, we also estimated the average marginal effects of cigarette tier prices, which is the change of probability in choosing a given cigarette tier resulting from a $¥ 1$ increase in the median price of that tier, accounting for movement into and out of a given tier (ie, net effects). We computed bootstrapped SEs for the average marginal effects, using 1000 repetitions and clustering at the individual level. Again, marginal effects were computed both for the full sample and by SES subgroup to facilitate analysis of the heterogeneous response to price changes.

\section{RESULTS}

\section{Sample characteristics}

Table 2 presents the descriptive statistics of the smokers in the full sample and by subgroup. Using the monthly income threshold of $¥ 3000$, about $62 \%$ of smokers in our sample had low incomes. In addition, approximately 55\% smokers had some high school and thus belong to the more educated subgroup. Over $96 \%$ of smokers are male across all subsamples. The average price of cigarettes purchased is $¥ 6.32$ in the full sample, which is virtually unchanged after adjusting for inflation. As expected, on average, high-SES smokers purchase more 
Table 2 Descriptive statistics, 2006-2009

\begin{tabular}{|c|c|c|c|c|c|}
\hline Variable description & Full sample & Low income & High income & Less educated & More educated \\
\hline \multicolumn{6}{|l|}{ Binary variables } \\
\hline Male & 0.963 & 0.954 & 0.978 & 0.940 & 0.982 \\
\hline \multicolumn{6}{|l|}{ Monthly household income } \\
\hline$<¥ 1000$ & 0.161 & 0.258 & - & 0.239 & 0.097 \\
\hline$¥ 1000-2999$ & 0.464 & 0.742 & - & 0.518 & 0.420 \\
\hline$¥ 3000-4999$ & 0.240 & - & 0.642 & 0.179 & 0.291 \\
\hline$\geq ¥ 5000$ & 0.134 & - & 0.358 & 0.065 & 0.191 \\
\hline \multicolumn{6}{|l|}{ Education } \\
\hline Primary school or less & 0.125 & 0.156 & 0.072 & 0.277 & - \\
\hline Middle school & 0.327 & 0.390 & 0.222 & 0.724 & - \\
\hline High school & 0.358 & 0.348 & 0.376 & - & 0.653 \\
\hline Beyond high school & 0.190 & 0.106 & 0.331 & - & 0.347 \\
\hline \multicolumn{6}{|l|}{ Continuous variables } \\
\hline \multirow[t]{2}{*}{ Age at baseline } & 50.8 & 51.4 & 49.6 & 54.1 & 48.0 \\
\hline & [12.3] & [12.4] & {$[12.4]$} & [12.3] & {$[11.8]$} \\
\hline \multicolumn{6}{|l|}{ Cigarette tier price } \\
\hline \multirow[t]{2}{*}{ Nominal } & 6.32 & 5.35 & 7.92 & 5.16 & 7.26 \\
\hline & [6.36] & [4.30] & {$[8.54]$} & {$[4.11]$} & {$[7.60]$} \\
\hline \multirow[t]{2}{*}{ Real, in 2006 terms } & 6.24 & 5.29 & 7.82 & 5.10 & 7.18 \\
\hline & {$[6.30]$} & {$[4.25]$} & {$[8.47]$} & {$[4.05]$} & {$[7.54]$} \\
\hline \multirow[t]{2}{*}{ Average daily cigarette consumption at baseline } & 17.7 & 17.9 & 17.0 & 18.6 & 16.8 \\
\hline & {$[10.8]$} & {$[11.3]$} & {$[9.75]$} & {$[11.3]$} & {$[10.3]$} \\
\hline Number of smoker-years & 8453 & 5288 & 3166 & 3820 & 4633 \\
\hline
\end{tabular}

expensive cigarettes than their low-SES counterparts. In addition, respondents across all subsamples smoked slightly less than one full pack per day. Although average cigarette price appears to be quite low, the high cigarette intake and relatively low income of Chinese smokers suggest that cigarette consumption likely accounts for a non-trivial portion of household expenditures. Based on observed cigarette consumption and prices, a rough estimate is that an average smoker with a monthly household income of $¥ 3000$ would spend $5.6 \%$ of this income on cigarettes.

\section{Regression estimates}

Table 3 presents the coefficient estimates from the mixed logit model for the full sample. These coefficients may be loosely understood as the effects of different factors on the likelihood of choosing a particular cigarette tier. ${ }^{10}$ The mean coefficient on price is negative and significant, suggesting that as cigarette tier price increases, the probability of purchasing cigarettes in that tier significantly diminishes. There is substantial heterogeneity in the value that smokers attach to cigarettes in a given tier, as indicated by the large, statistically significant SDs of the coefficients on the alternative-specific constants that is, on the tier dummies.

In general, one would expect cigarettes in more expensive tiers to have higher quality and to be more attractive to smokers, holding all else constant. This appears to be the case as the tier dummy coefficients decrease steadily from Tier 2 to 4. Interestingly, Tier 1 has a lower mean coefficient estimate than Tier 2. There are two possible explanations for why, all else equal, smokers may attach greater value to cigarettes in Tier 2 than in Tier 1. First, cigarettes in the highest tier are most commonly purchased as gifts in China, ${ }^{1}$ therefore the majority of smokers may not value cigarettes in this tier as much when purchased for self-consumption. Second, most consumers of very expensive cigarettes may use them as a type of 'status good', ${ }^{11}$ that is, to signal that person's economic and social status to others, rather than for normal everyday consumption, which would limit the occasions in which very expensive cigarettes may be needed or yield very high utility.

Smoker characteristics also have significant effects on the choice of cigarette brand tiers as illustrated by the coefficients on demographic covariates in table 3 . The probability of choosing more expensive tiers decreases significantly with age. In addition, smokers with a low income and less education are far more likely to purchase cigarettes in lower tiers. The substantial heterogeneity in brand choice by SES in the full model motivates further analysis by subgroup.

\section{Marginal effects of a price change by SES subgroup}

In order to further interpret the magnitudes of brand-switching, we calculate the average marginal effect of each cigarette price, defined as the effect of a $¥ 1$ price increase for a given tier on the predicted probability of choosing that tier. This $¥ 1$ increment corresponds to a $20 \%$ increase in the median price of cigarettes in our sample ( $¥ 5$ ).

Table 4 shows the marginal own-price effects for the full sample and by SES subgroup. For each tier, increasing the price by $¥ 1$ while holding the prices of other tiers constant is associated with a statistically significant decrease in the probability of choosing that tier. For the full sample of smokers, from the most expensive to cheapest tier, the own-price effect is a decrease of $1.45 \%$ points, $3.27 \%$ points, $4.48 \%$ points and $2.67 \%$ points. Correspondingly, the share of smokers in each tier decreases by $10.3 \%, 11.4 \%, 10 \%$ and $21.1 \%$ in response to a $¥ 1$ increase in tier price. These magnitudes imply that smokers in the middle two tiers are most likely to respond to a price 
Table 3 Regression results from mixed logit model

\begin{tabular}{|c|c|c|c|c|}
\hline & No interaction & Interacted with Tier 1 & Interacted with Tier 2 & Interacted with Tier 3 \\
\hline \multicolumn{5}{|l|}{ Random coefficients } \\
\hline Cigarette tier price-mean & $\begin{array}{l}-0.314^{* * *} \\
(0.049)\end{array}$ & & & \\
\hline Cigarette tier price-SD & $\begin{array}{l}0.221 * * * \\
(0.031)\end{array}$ & & & \\
\hline Constant-mean & & $\begin{array}{l}4.565^{* * *} \\
(1.006)\end{array}$ & $\begin{array}{l}5.101^{* * *} \\
(0.777)\end{array}$ & $\begin{array}{l}2.558^{* * *} \\
(0.631)\end{array}$ \\
\hline Constant-SD & & $\begin{array}{l}1.119 * * * \\
(0.256)\end{array}$ & $\begin{array}{l}1.159 * * * \\
(0.129)\end{array}$ & $\begin{array}{l}1.524 * * * \\
(0.105)\end{array}$ \\
\hline \multicolumn{5}{|l|}{ Fixed coefficients } \\
\hline Male & & $\begin{array}{l}0.961 \\
(0.614)\end{array}$ & $\begin{array}{l}0.803^{* *} \\
(0.340)\end{array}$ & $\begin{array}{l}0.760 * * * \\
(0.240)\end{array}$ \\
\hline Age & & $\begin{array}{l}-0.087^{* * *} \\
(0.009)\end{array}$ & $\begin{array}{l}-0.075^{* * *} \\
(0.008)\end{array}$ & $\begin{array}{l}-0.033^{* * *} \\
(0.007)\end{array}$ \\
\hline Income: <¥1000 & & $\begin{array}{l}-3.644^{* * *} \\
(0.385)\end{array}$ & $\begin{array}{l}-2.692^{* * *} \\
(0.308)\end{array}$ & $\begin{array}{l}-1.009 * * * \\
(0.291)\end{array}$ \\
\hline Income: $¥ 1000-2999$ & & $\begin{array}{l}-2.509^{* * *} \\
(0.310)\end{array}$ & $\begin{array}{l}-1.544^{* * *} \\
(0.267)\end{array}$ & $\begin{array}{l}-0.512^{* *} \\
(0.262)\end{array}$ \\
\hline Income: $¥ 3000-4999$ & & $\begin{array}{l}-1.265^{* * *} \\
(0.324)\end{array}$ & $\begin{array}{l}-0.648^{* *} \\
(0.286)\end{array}$ & $\begin{array}{l}-0.386 \\
(0.281)\end{array}$ \\
\hline Income: $\geq ¥ 5000$ (omitted) & & & & \\
\hline Education: Primary school and belo & & & & \\
\hline Education: Middle school & & $\begin{array}{l}0.496 \\
(0.340)\end{array}$ & $\begin{array}{l}0.499 * * \\
(0.243)\end{array}$ & $\begin{array}{l}0.678^{* * *} \\
(0.212)\end{array}$ \\
\hline Education: High school & & $\begin{array}{l}1.337^{* * *} \\
(0.330)\end{array}$ & $\begin{array}{l}1.204^{* * *} \\
(0.254)\end{array}$ & $\begin{array}{l}0.899 * * * \\
(0.225)\end{array}$ \\
\hline Education: Beyond high school & & $\begin{array}{l}2.505^{* * *} \\
(0.380)\end{array}$ & $\begin{array}{l}2.039 * * * \\
(0.310)\end{array}$ & $\begin{array}{l}1.277^{* * *} \\
(0.260)\end{array}$ \\
\hline Cigarette consumption at Wave 1 & & $\begin{array}{l}-0.011 \\
(0.009)\end{array}$ & $\begin{array}{l}-0.016^{* *} \\
(0.008)\end{array}$ & $\begin{array}{l}-0.005 \\
(0.007)\end{array}$ \\
\hline Wave fixed effects & Yes & & & \\
\hline City fixed effects & Yes & & & \\
\hline Number of persons & 3477 & & & \\
\hline Number of person-years & 8552 & & & \\
\hline Number of observations & 34208 & & & \\
\hline
\end{tabular}

change by switching to another tier. In part, this reflects the constraints that consumers on the extremes face: smokers of discount brands (Tier 4) have no ability to trade down and smokers of premium brands (Tier 1) have no ability to trade up.

Marginal own-price effects for the full sample of smokers mask important heterogeneity in price responses by SES subgroup. Rows 2-7 of table 4 present the marginal own-price effects for each subgroup: low-income, high-income, less educated and more educated smokers. In all cases but one, lowincome and less educated smokers are far more likely to switch tiers compared to their high-SES counterparts, as demonstrated from the $p$ values of $z$-scores of subgroup differences in marginal propensity of switching. Low-income or less educated smokers who initially purchased cigarettes in Tier 3 are most responsive to prices: a $¥ 1$ rise in prices increases the likelihood of switching tiers by $5.6 \%$ points $(11.1 \%$ decrease in tier share) for low-income smokers and $7.2 \%$ points $(14.3 \%$ decrease in tier share) for less educated smokers, compared to $1.6 \%(4.7 \%$ decrease in tier share) and $3 \%$ points $(7.5 \%$ decrease in tier share) for the corresponding high-SES groups. By contrast, the probability of brand switching for those who start in Tier 1 seems to be quite small and relatively stable across SES group. Even though the $p$ value still shows significant difference between high-income and low-income smokers in Tier 1, the $\mathrm{z}$-score of between-group difference is much smaller compared to other tiers. Again, this would be consistent with gift-giving and the consumption of status goods as explained earlier, as these special purposes make it less likely that cigarettes in lower tiers will serve as good substitutes for premium cigarettes, hence lowering the likelihood of brand switching out of Tier 1.

In addition to own-price effects, the mixed logit estimates provide the cross-price effects of, say, a price change in Tier 2 on the probability of choosing Tiers 1,3 and 4 . The relative size of the cross-price effects for higher versus lower tiers provides a measure of the share of smokers who traded up to a higher quality tier versus the share who traded down to a lower quality tier following a $¥ 1$ increase in tier price. This procedure is only informative for the middle tiers for which individuals are able 
Table 4 Marginal own-price effects: full sample and by subgroup

\begin{tabular}{|c|c|c|c|c|}
\hline & Tier 1 & Tier 2 & Tier 3 & Tier 4 \\
\hline \multirow[t]{3}{*}{ Full Sample } & $-1.445^{* * *}$ & $-3.268^{* * *}$ & $-4.484^{* * *}$ & $-2.665^{* * *}$ \\
\hline & $(0.023)$ & $(0.029)$ & $(0.017)$ & $(0.030)$ \\
\hline & {$[-10.33]$} & {$[-11.39]$} & {$[-10.04]$} & {$[-21.08]$} \\
\hline \multicolumn{5}{|l|}{ Subgroup analysis } \\
\hline Low-income smokers & $-1.308^{* * *}$ & $-3.203^{* * *}$ & $-5.648 * * *$ & $-3.733^{* * *}$ \\
\hline \multirow[t]{2}{*}{ (Income $<¥ 3000$ ) } & $(0.023)$ & $(0.041)$ & $(0.021)$ & $(0.041)$ \\
\hline & {$[-13.52]$} & {$[-13.90]$} & {$[-11.11]$} & {$[-22.68]$} \\
\hline High-income smokers & $-1.141^{* * *}$ & $-1.862 * * *$ & $-1.601^{* * *}$ & $-0.753^{* * *}$ \\
\hline \multirow[t]{2}{*}{ (Income $\geq ¥ 3000$ ) } & $(0.020)$ & $(0.014)$ & $(0.016)$ & $(0.015)$ \\
\hline & {$[-5.37]$} & {$[-4.87]$} & {$[-4.66]$} & {$[-12.12]$} \\
\hline Z-score of between-group difference & 5.48 & 30.95 & 153.29 & 68.26 \\
\hline$p>|z|$ & $<0.0001$ & $<0.0001$ & $<0.0001$ & $<0.0001$ \\
\hline Less educated smokers & $-1.374^{* * *}$ & $-3.994^{* * *}$ & $-7.171 * * *$ & $-4.872^{* * *}$ \\
\hline \multirow[t]{2}{*}{ (Less than high school) } & $(0.034)$ & $(0.067)$ & $(0.032)$ & $(0.065)$ \\
\hline & {$[-15.62]$} & {$[-17.08]$} & {$[-14.27]$} & {$[-27.73]$} \\
\hline More educated smokers & $-1.353^{* * *}$ & $-2.713^{* * *}$ & $-2.967^{* * *}$ & $-1.520^{* * *}$ \\
\hline \multirow[t]{2}{*}{ (At least some high school) } & $(0.029)$ & $(0.027)$ & $(0.024)$ & $(0.027)$ \\
\hline & {$[-7.17]$} & {$[-8.05]$} & {$[-7.53]$} & {$[-19.01]$} \\
\hline Z-score of between-group difference & 0.470 & 17.73 & 105.1 & 47.62 \\
\hline $\mathrm{p}>|z|$ & 0.64 & $<0.0001$ & $<0.0001$ & $<0.0001$ \\
\hline
\end{tabular}

to substitute bidirectionally. Figure 1 shows the percentage of switchers who trade down by tier and subgroup. Among switchers, those who purchased cigarettes in Tier 3 at baseline are on average more than twice as likely to trade up to more expensive cigarettes $(70.9 \%)$ than to trade down to the cheapest tier (29.1\%). In contrast, those who purchased cigarettes in Tier 2 at baseline are less inclined to trade up (38.9\%) than to trade down (61.1\%).

There are large differences across subgroups in the percentage of switchers who trade down as opposed to trading up. In all cases, the low-income and less educated groups are more likely to trade down. Among switchers who purchased Tier 3 cigarettes at baseline, $53.4 \%$ of low-income smokers traded down compared to $23.3 \%$ of high-income smokers. The parallel estimates of down-trading for switchers who purchased Tier 2 cigarettes at baseline are $81.2 \%$ of low-income smokers and $63 \%$ of high-income smokers. The differences by schooling are also stark: for switchers starting in Tier 3, 56.5\% of less educated smokers trade down versus $35.1 \%$ of more educated smokers; and for those starting in Tier 2, $82.1 \%$ of less educated smokers trade down versus $69.9 \%$ of more educated smokers.

\section{DISCUSSION}

We find large heterogeneity in the brand-switching behaviour of smokers in response to price changes. We find that SES and the starting tier are important sources of heterogeneity in how smokers respond to price changes. Specifically, low-income and less educated smokers are far more likely to engage in brand switching compared to high-income or more educated workers:
Figure 1 Percentage of switchers who trade down.

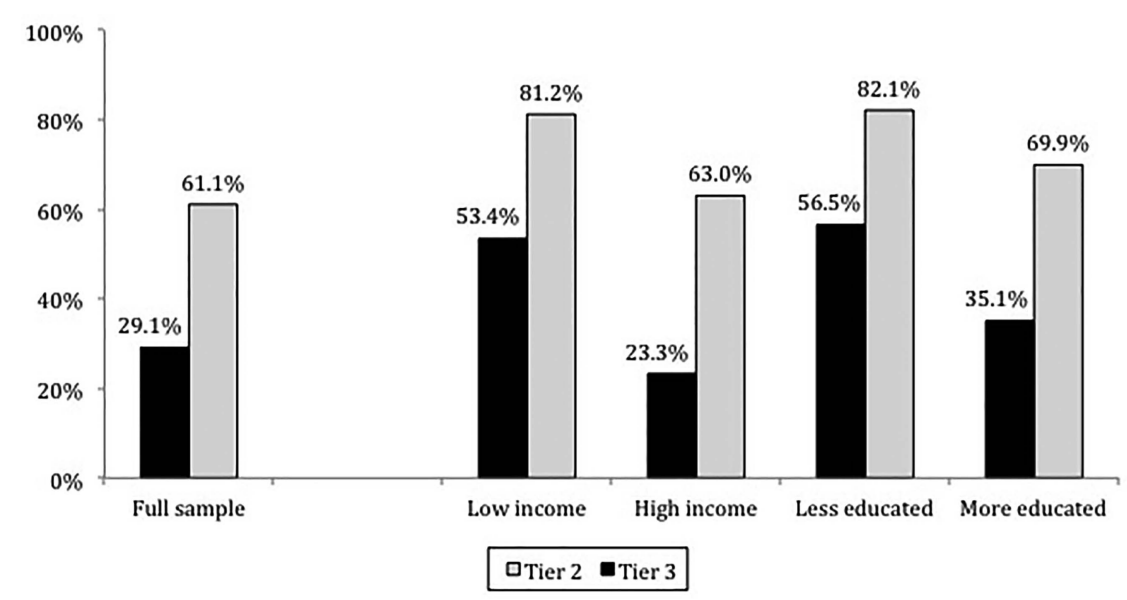


on net, approximately $11 \%$ to $23 \%$ low-income smokers and $14 \%$ to $28 \%$ less educated smokers in a given tier switch to an alternative tier in response to a $¥ 1$ increase in the price of the starting tier, whereas only about $5 \%$ to $12 \%$ high-income and $7 \%$ to $19 \%$ more educated smokers do so. The difference in marginal effects is statistically significant across subgroups for each tier except between less and more educated smokers in Tier 1.

In addition, the likelihood of switching from the low and middle tiers is much higher than the likelihood of switching from the highest tier, especially for low-income and less educated smokers. Across all models, low-income and less educated groups are more likely to trade down compared to their high SES counterparts. Based on the results from table 4 and figure 1, a $¥ 1$-increase in the price of a given tier induces $1.3-3 \%$ of all lowincome smokers and $1.4-4.1 \%$ of all less educated smokers to switch to a cheaper tier, whereas only $1-1.2 \%$ high-income smokers and 1-1.9\% more educated smokers do so.

It is worth noting that from the mixed logit model, the estimates of SDs for the random variables-in this case the coefficients on price and tier fixed effects-are all statistically significant and quite large in magnitude, suggesting that there is substantial variation in smokers' sensitivity to price and taste for different cigarette tiers, thereby justifying the use of mixed logit model. In comparison, conditional logit model (results not shown) tends to underestimate the magnitude of the price coefficient by restricting it to be fixed across smokers.

One caveat in interpreting the results of our study is that we only examine brand switching across tiers. To the extent that smokers may switch brands within a given tier, our results may still underestimate the true extent of brand-switching among Chinese smokers. ${ }^{3}$ However, since the three lowest tiers in our classification in which smokers are more sensitive to price all have reasonably narrow price ranges (approximately $¥ 3$, or $\$ 0.5$ ), it is unlikely that our method would severely underestimate the magnitude of brand-switching, especially for lowincome and less educated smokers who are much more likely to consume cigarettes in one of the three lowest tiers.

Overall, we find evidence of only moderate magnitude of smokers switching to less expensive tiers in response to price increase, as shown in our back-of-envelope calculation (Paragraph 2 of this section). This has at least three implications for tobacco control policy. First, brand switching does not appear to be a valid reason for the Chinese government to avoid raising tobacco taxes. Given the relatively small magnitude of trading down among different SES subgroups of smokers, we would expect this factor to have minimal impact on the effectiveness of a cigarette tax increase. Second, our study indicates that brand switching would be most likely to occur following tax adjustments that alter the relative prices of cigarettes across tiers. The 2009 tax reform, though it left brand-specific retail prices unchanged, set higher allowable profit margins for premium brands. This shifted production toward premium brands and decreased the availability of cheaper cigarettes, thus moving the peak of the distribution of cigarette prices to the right. When low-priced cigarettes are no longer available, smokers who view higher-priced cigarettes as a reasonable substitute will be likely to trade up, as evidenced by the data. Future tax reform needs to take this behaviour into account by equalising the cross-tier incentives of cigarette manufacturers to produce one price tier versus another, thereby discouraging both up-trading and down-trading. Third, there may be an important role for public education aimed at shattering the high-status image of high-end cigarettes. The denormalisation of smoking in Western countries began with the high-SES population. If the same holds true in China, then we would expect that, as increasing numbers of wealthier Chinese smokers quit smoking, the demand for premium cigarettes should decline. The result would be a compression of the price distribution. More research is needed to understand the motivations of Chinese smokers for consuming high-end cigarettes.

Furthermore, the fact that low-income or less educated smokers are more likely to engage in brand switching highlights how price-sensitive these groups are. It is unlikely that these subgroups would be willing to sacrifice a significant portion of income just to maintain consumption of cigarettes from which they derive limited utility. A carefully designed tax reform, namely one that discourages brand switching, holds promise for decreasing cigarette consumption among low-SES smokers, rather than shouldering them with a greater financial burden. As we have also argued in previous work, ${ }^{3}$ an increase in ad valorem tax rates, imposed as a percentage of price, would further amplify the cigarette price spread, creating more incentives for smokers to trade down to cheaper cigarettes. By contrast, a specific excise tax, a fixed amount per unit, would reduce differences in relative tier prices, thereby discouraging down-trading. A specific excise tax is the preferred policy instrument for curbing brand switching, yet China's current excise tax is an insignificant $¥ 0.06$ ( $\$ 0.01$ ) per pack. The overall tobacco tax rate in China is only $40-46 \%$ of retail prices, far below the WHO standard of $70 \% .^{3}$ Hence there is ample scope for China to raise its specific excise tax on tobacco.

We believe that the issue of the potential regressivity of taxes is an important one. While we are not aware of any studies documenting a differential adverse impact of taxation on low-SES groups in China, studies in other settings have raised this concern. ${ }^{12}$ It is an empirical question whether tobacco taxes in China are regressive. To the extent that they are, we believe that transfer payments may be an effective policy instrument for the Chinese government to address the differential financial and health burdens from smoking experienced by low-SES groups. In light of the country's recent experience with healthcare reform, the revenues from increased tobacco taxes may be used as subsidies on insurance premiums or healthcare expenditures, to be directed toward socioeconomically disadvantaged groups.

Finally, our case study of China's cigarette market may also be instructive for other countries in Asia. India, Vietnam, Indonesia and certain other countries have a large share of low-income smokers and the availability of cheap tobacco products. Our findings regarding brand switching by SES group in China suggest that an increase on excise taxes for tobacco products may also be effective in other contexts that share similar characteristics to the tobacco market as China.

\section{What this paper adds}

- This paper is the first to examine brand choice behaviour by socioeconomic status of smokers in China.

- The finding is important in assessing the two rationales commonly cited by the Chinese government against tax increase, namely, the unfair burden it places on low-income smokers and the ability of consumers to undo a tax's health effects by switching to cheaper brands.

- Mixed logit model offers a flexible and rigorous approach for identifying the impact of cigarette prices on purchasing behaviour. 
Acknowledgements The authors work has benefitted from input from Frank Chaloupka, Ben Handel, Jiun-Hua Su and Ken Train. The authors thank Qiang Li for access to the retail price data and Anne C K Quah for administrative support.

Contributors $\mathrm{J}$ analysed the data, interpreted the results and drafted the manuscript. JSW conceived and designed the study, analysed the data, interpreted the results and contributed to drafting and revisions of the manuscript. T-wH conceived and designed the study and contributed to drafting and revisions of the manuscript. GTF supervised data collection and commented on an earlier draft of the manuscript. JY supervised data collection. All authors reviewed and approved the final manuscript. The corresponding author had full access to all data and final responsibility for the decision to submit the report for publication.

Funding JSW was supported by a grant from the US National Institute on Aging (T32-AG000246). T-wH was supported by a grant from the US Fogarty International Center (R01-TW009295). Additional support was provided to Geoffrey T. Fong from a Senior Investigator Award from the Ontario Institute for Cancer Research and a Prevention Scientist Award from the Canadian Cancer Society Research Institute. The ITC China Project was supported by grants from the US National Cancer Institute (R01-CA125116 and P01-CA138389), the Roswell Park Transdisciplinary Tobacco Use Research Center (P50-CA111236), the Canadian Institutes of Health Research (57897, 79551 and 115216) and the Chinese Center for Disease Control and Prevention.

Competing interests None declared.

Patient consent Obtained.

Ethics approval The ITC China Surveys were cleared for ethics by Research Ethics Boards or International Review Boards at the University of Waterloo (Canada), Roswell Park Cancer Institute (USA) and the Chinese Center of Disease Control and Prevention.

Provenance and peer review Not commissioned; externally peer reviewed.

\section{REFERENCES}

1 Hu T, Lee AH, Mao Z. WHO Framework Convention on Tobacco Control in China: barriers, challenges and recommendations. Glob Health Promot 2013;20:13-22.

2 Hu T, Mao Z, Shi J. Recent tobacco tax rate adjustment and its potential impact on tobacco control in China. Tob Control 2010;19:80-2.

3 White JS, Li J, Hu T, et al. The effect of cigarette prices on brand-switching in China: a longitudinal analysis of data from the ITC China Survey. Tob Control 2014;23:i54-60.

4 Zheng R, Gao S, Hu T. Tobacco tax and tobacco control: global experience and its application in China. Finance Trade Econ 2013;3:44-53.

5 Gao S, Zheng R, Hu T. Can increases in the cigarette tax rate be linked to cigarette retail prices? Solving mysteries related to the cigarette pricing mechanism in China. Tob Control 2011;21:560-2.

6 Tong $\mathrm{E}$, Tao $\mathrm{M}$, Xue Q, et al. China's tobacco industry and the world trade organization. In: Hu T, ed. Tobacco control policy analysis in China. Hackensack, NJ: World Scientific Publishing Co., 2008:211-44.

7 Train KE. Discrete choice methods with simulation. New York, NY: Cambridge University Press, 2009.

8 National Bureau of Statistics of China (2014). Urban Resident Income Data, 2007. http://data.stats.gov.cn/workspace/index?m=hgnd (accessed 20 Apr 2014).

9 National Bureau of Statistics of China (2011). 2010 Sixth National Population Census Report. http://www.stats.gov.cn/tjsj/tjgb/rkpcgb/qgrkpcgb/201104/ t20110428_30327.html (accessed 20 Apr 2014).

10 Train KE, Winston C. Vehicle choice behavior and the declining market share of US automakers. Int Econ Rev 2007;48:1469-96.

11 Chen X, Zhang X. Costly posturing: relative status, ceremonies and early child development. Unpublished working paper. 2011.

12 Colman GJ, Remler DK. Vertical equity consequences of very high cigarette tax increases: if the poor are the ones smoking, how could cigarette tax increases be progressive? J Policy Anal Manage 2008;27:376-400. 